Virginia Commonwealth University VCU Scholars Compass

\title{
Highly porous photoluminescent diazaborole- linked polymers: synthesis, characterization, and application to selective gas adsorption
}

Zafer Kahveci

Virginia Commonwealth University

Ali K. Sekizkardes

Virginia Commonwealth University

Ravi K. Arvapally

Virginia Commonwealth University

Logan Wilder

Virginia Commonwealth University

Hani M. El-Kaderi

Virginia Commonwealth University

Follow this and additional works at: http://scholarscompass.vcu.edu/chem_pubs

Part of the Chemistry Commons

This journal is (C) The Royal Society of Chemistry 2017

\section{Downloaded from}

http://scholarscompass.vcu.edu/chem_pubs/70

This Article is brought to you for free and open access by the Dept. of Chemistry at VCU Scholars Compass. It has been accepted for inclusion in Chemistry Publications by an authorized administrator of VCU Scholars Compass. For more information, please contact libcompass@vcu.edu. 


\section{A) Check for updates}

Cite this: Polym. Chem., 2017, 8 , 2509

Received 14th December 2016 Accepted 27th March 2017

DOI: $10.1039 /$ c6py02156e

rsc.li/polymers

\section{Highly porous photoluminescent diazaborole- linked polymers: synthesis, characterization, and application to selective gas adsorption $\uparrow$}

\author{
Zafer Kahveci, (D) Ali K. Sekizkardes, Ravi K. Arvapally, Logan Wilder and \\ Hani M. El-Kaderi*
}

\begin{abstract}
The formation of boron-nitrogen ( $\mathrm{B}-\mathrm{N}$ ) bonds has been widely explored for the synthesis of small molecules, oligomers, or linear polymers; however, its use in constructing porous organic frameworks remains very scarce. In this study, three highly porous diazaborole-linked polymers (DBLPs) have been synthesized by condensation reactions using 2,3,6,7,14,15-hexaaminotriptycene and aryl boronic acids. DBLPs are microporous and exhibit high Brunauer-Emmett-Teller surface area (730-986 $\mathrm{m}^{2} \mathrm{~g}^{-1}$ ) which enable their use in small gas storage and separation. At ambient pressure, the amorphous polymers show high $\mathrm{CO}_{2}$ (DBLP-4: $4.5 \mathrm{mmol} \mathrm{g}^{-1}$ at $273 \mathrm{~K}$ ) and $\mathrm{H}_{2}$ (DBLP-3: $2.13 \mathrm{wt} \%$ at $77 \mathrm{~K}$ ) uptake while their physicochemical nature leads to high $\mathrm{CO}_{2} / \mathrm{N}_{2}(35-42)$ and moderate $\mathrm{CO}_{2} / \mathrm{CH}_{4}$ (4.9-6.2) selectivity. The electronic impact of integrating diazaborole moieties into the backbone of these polymers was investigated for DBLP-4 which exhibits green emission with a broad peak ranging from 350 to $680 \mathrm{~nm}$ upon excitation with $340 \mathrm{~nm}$ in DMF without photobleaching. This study demonstrates the effectiveness of $\mathrm{B}-\mathrm{N}$ formation in targeting highly porous frameworks with promising optical properties.
\end{abstract}

\section{Introduction}

Porous organic polymers (POPs) have attracted significant attention in recent years due to their potential in gas storage and separation, conductivity, catalysis, electronics, and chemical sensing. ${ }^{1-6}$ POPs are synthesized using versatile synthetic routes while their chemical composition and textural properties can be tailored to optimize their multifaceted uses. During synthesis, the covalent nature of POPs renders them amorphous unless thermodynamic and kinetic parameters are controlled as in the case of covalent organic frameworks (COFs) which form microcrystalline materials wherein the building units linked by $\mathrm{B}-\mathrm{O}, \mathrm{C}-\mathrm{N}$, and $\mathrm{B}-\mathrm{N}$ bonds. $^{7-11}$ Amorphous POPs prepared from the formation of these bonds and $\mathrm{C}-\mathrm{C}$ bonds are documented in literature and they include PAFs, ${ }^{12}$ triazine-based polyimides (TPIs), ${ }^{13}$ triptycene-based polymers of intrinsic microporosity (Trip(Et)-PIM), ${ }^{14}$ polycarbazoles (CPOPs) ${ }^{15}$ imine-linked microporous polymers, ${ }^{16,17}$ azo-linked polymers (ALPs), ${ }^{18}$ and benzimidazole-linked polymers (BILPs). ${ }^{19-23}$ Surprisingly and in spite of the growing

Department of Chemistry, Virginia Commonwealth University, Richmond, Virginia 23284-2006, USA.E-mail: helkaderi@vcu.edu

$\dagger$ Electronic supplementary information (ESI) available: Spectral and physical characterization of diazaborole-linked polymers and their gas uptake and selectivity studies. See DOI: 10.1039/c6py02156e interest in this area, there are only very few examples of porous networks preparation through $\mathrm{B}-\mathrm{N}$ bond formation, namely, borazine-linked polymers (BLPs) ${ }^{24-27}$ and B,N-containing cross-linked polymers (PPs-BN) ${ }^{28}$ We have demonstrated that the formation of borazine $\left(\mathrm{B}_{3} \mathrm{~N}_{3}\right.$, Fig. $\left.1 \mathrm{~B}\right)$ which is analogous to boroxine $\left(\mathrm{B}_{3} \mathrm{O}_{3}\right.$, Fig. $\left.1 \mathrm{~A}\right)$ in COFs can lead to porous frameworks that show good thermal stability and interesting gas
(A)<smiles>CC(C)B1OB(C(C)C)OB(C(C)(C)C)O1</smiles>

boroxine
(B)<smiles>CC(C)B1NB2CCN(C(C)C)B(N2)B(C(C)C)N1</smiles>

(C)<smiles>CC(C)B1Oc2cc(C(C)C)c(C(C)C)cc2O1</smiles>

boronate-ester
(D)<smiles>CCB1Nc2cc(C(C)(C)C)c(C(C)(C)C)cc2N1</smiles>

diazaborole
Fig. 1 Boroxine (A) and boronate-ester (C) building blocks and their borazine (B) and diazaborole analogs. 
uptake properties. ${ }^{24-27}$ Another effective method for boron incorporation into COFs is through condensation reactions that lead to boronate-ester linkage formation $\left(\mathrm{C}_{2} \mathrm{O}_{2} \mathrm{~B}\right.$, Fig. $\left.1 \mathrm{C}\right)$. To expand on the use of $\mathrm{B}-\mathrm{N}$ bond in constructing porous networks we envisioned that the formation of diazaborole $\left(\mathrm{C}_{2} \mathrm{~N}_{2} \mathrm{~B}\right.$, Fig. 1D) would lead to new porous networks for potential use in gas storage and optical applications. Although 5-membered diazaborole rings have been used to modify the photophysical properties of linear polymers as well as small molecules, ${ }^{29-32}$ their use in porous networks remains unprecedented to the best of our knowledge.

In this study, we report the first use of $\mathrm{B}-\mathrm{N}$ bond formation to construct highly porous diazaborole-linked polymers (DBLPs) and investigate their porosity and application in small gas storage. DBLPs are highly porous and show high $\mathrm{CO}_{2}$ and $\mathrm{H}_{2}$ uptake, high $\mathrm{CO}_{2}$ selectivity over $\mathrm{N}_{2}$ and $\mathrm{CH}_{4}$ as well as high thermal stability.

\section{Experimental methods}

All starting materials, unless noted otherwise, were obtained from Acros Organics and used without further purification. 1,2,4,5-Benzenetetramine tetrahydrochloride (BTA), triptycene, chloroform (stabilized with amylene) and $\mathrm{N}$ - $\mathrm{N}$-dimethylformamide (DMF) were purchased from Aldrich Chemical Co. and used without further purification. Solvents were dried by distillation from $\mathrm{Na}$ (toluene) or $\mathrm{Na}$ /benzophenone (THF). 1,3,5-benzenetriboronic acid (BTBA) $)^{33,34}$ and 2,3,6,7,14,15hexaaminotriptycene $(\mathrm{HATT})^{20}$ were synthesized according to published methods. All products were handled under nitrogen atmosphere using glovebox or Schlenk line techniques. Solution ${ }^{1} \mathrm{H}$ NMR spectra were taken by Varian Mercury$300 \mathrm{MHz}$ NMR spectrometer (75 $\mathrm{MHz}$ carbon frequency). Solid-state ${ }^{13} \mathrm{C}$ cross-polarization magic angle spinning (CP-MAS) NMR spectra of solid samples were obtained by Spectral Data Services, Inc. Spectra were obtained using Tecmag-based NMR spectrometer, operated at a $\mathrm{H}-1$ frequency of $363 \mathrm{MHz}$, using contact time of $1 \mathrm{~ms}$ and delay of three seconds for CP-MAS experiments. Thermogravimetric analysis (TGA) was carried out by a TA Instruments Q-5000IR series thermal gravimetric analyzer using $50 \mu \mathrm{L}$ platinum pans under flow of $\mathrm{N}_{2}$ gas with heating rate of $5{ }^{\circ} \mathrm{C} \mathrm{min}^{-1}$. To obtain Scanning Electron Microscopy (SEM) images, each sample was dispersed onto a sticky carbon surface attached to a flat aluminum sample holder. Then, the sample was coated with platinum at pressure of $1 \times 10^{-5}$ mbar in nitrogen atmosphere for 90 seconds before imaging. SEM images were taken by a Hitachi SU-70 Scanning Electron Microscope. Powder X-ray diffraction patterns were collected on a Panalytical X'pert pro multipurpose diffractometer (MPD) with $\mathrm{Cu} \mathrm{K} \alpha$ radiation. FT-IR spectra were obtained by a Nicolet-Nexus 670 spectrometer having an attenuated total reflectance accessory. Porosity and gas sorption experiments were carried out using a Quantachrome Autosorb iQ volumetric analyzer using UHP grade adsorbates. All samples were degassed at $120{ }^{\circ} \mathrm{C}$ under vacuum before gas sorption measurements. Pore Size Distribution (PSD) was calculated from Ar isotherms using spherical/cylindrical pore (zeolite) NLDFT adsorption branch model.

\subsection{Preparation of DBLP-3}

1,4-Benzenediboronic acid (BDBA) (42 $\mathrm{mg}, 0.25 \mathrm{mmol}$ ) and 2,3,6,7,14,15-hexaaminotriptycene (HATT) (100 mg, $0.18 \mathrm{mmol}$ ) were grained into a mortar and suspended in $30 \mathrm{~mL}$ of dry $\mathrm{N}$ - $\mathrm{N}$-dimethylformamide (DMF) under a nitrogen atmosphere in a $100 \mathrm{~mL}$ Schlenk flask. After 10 minutes bubbling nitrogen gas, the mixture was sonicated for 30 minutes. The flask was transferred into an oven and gradually heated until $130{ }^{\circ} \mathrm{C}$ then kept at that temperature for three days. Then the flask was taken into glovebox, filtered over medium glass frit and washed with dry DMF and dry acetone. The product was soaked in dry acetone/DMF (50:50 v:v) mixture for 12 hours at which point the solvent was decanted and only dry acetone was added for 12 hours more. Decantation and addition of fresh acetone was repeated once more. The solid was then filtrated and activated at $120{ }^{\circ} \mathrm{C}$ under reduced pressure for 16 hours to afford DBLP-3 (53 mg, 65\% yield) as a greenish solid. Anal. Calcd for $\mathrm{C}_{58} \mathrm{H}_{34} \mathrm{~B}_{6} \mathrm{~N}_{12}$ : C, 71.83\%; H, 4.16\%; N, 17.33\%; Found: C, 59.82\%; H, 4.19\%; N, 12.53\%.

\subsection{Preparation of DBLP-4}

This polymer was synthesized following the methods mentioned above for DBLP-3 using 1,3,5-benzenetris (4-phenylboronic acid) (BTPA) (46.6 mg, $0.094 \mathrm{mmol}$ ) and 2,3,6,7,14,15hexaaminotriptycene (HATT) (60 mg, $0.107 \mathrm{mmol})$. After drying, the final product DBLP-4 was obtained as off-white solid (42 mg, 66\% yield). Anal. Calcd for $\mathrm{C}_{44} \mathrm{H}_{29} \mathrm{~B}_{3} \mathrm{~N}_{6}$ : C, $78.39 \%$; H, 4.34\%; N, 12.47\%. Found: C, 70.22\%; H, 4.99\%; N, $8.52 \%$.

\subsection{Preparation of DBLP-5}

This polymer was synthesized following the methods mentioned above for DBLP-3 using tetra(4-dihydroxyborylphenyl) methane (TBPM) (40 mg, $0.080 \mathrm{mmol}$ ) and 2,3,6,7,14,15-hexaaminotriptycene (HATT) (60 mg, $0.107 \mathrm{mmol}$ ). After drying, the final product DBLP-5 was obtained as off-white solid (58 mg, 60\% yield). Anal. Calcd for $\mathrm{C}_{155} \mathrm{H}_{104} \mathrm{~B}_{12} \mathrm{~N}_{24}$ : C, 76.54\%; H, 4.31\%; N, 13.82\%. Found: C, 66.79\%; H, 4.72\%; N, 8.14\%.

Note: Organoboron compounds typically give lowered carbon and nitrogen values in elemental microanalysis due to the formation of non-combustible boron carbide and boron nitride byproducts. ${ }^{24-27}$

\section{Results and discussion}

\subsection{Synthesis and characterization of DBLPs}

The synthesis of all DBLPs was carried out by condensation reactions between aryl boronic acids and 2,3,6,7,14,15-hexaaminotriptycene (HCl salt) in anhydrous DMF under nitrogen atmosphere at $130{ }^{\circ} \mathrm{C}$ for 3 days as shown in Scheme 1. All 


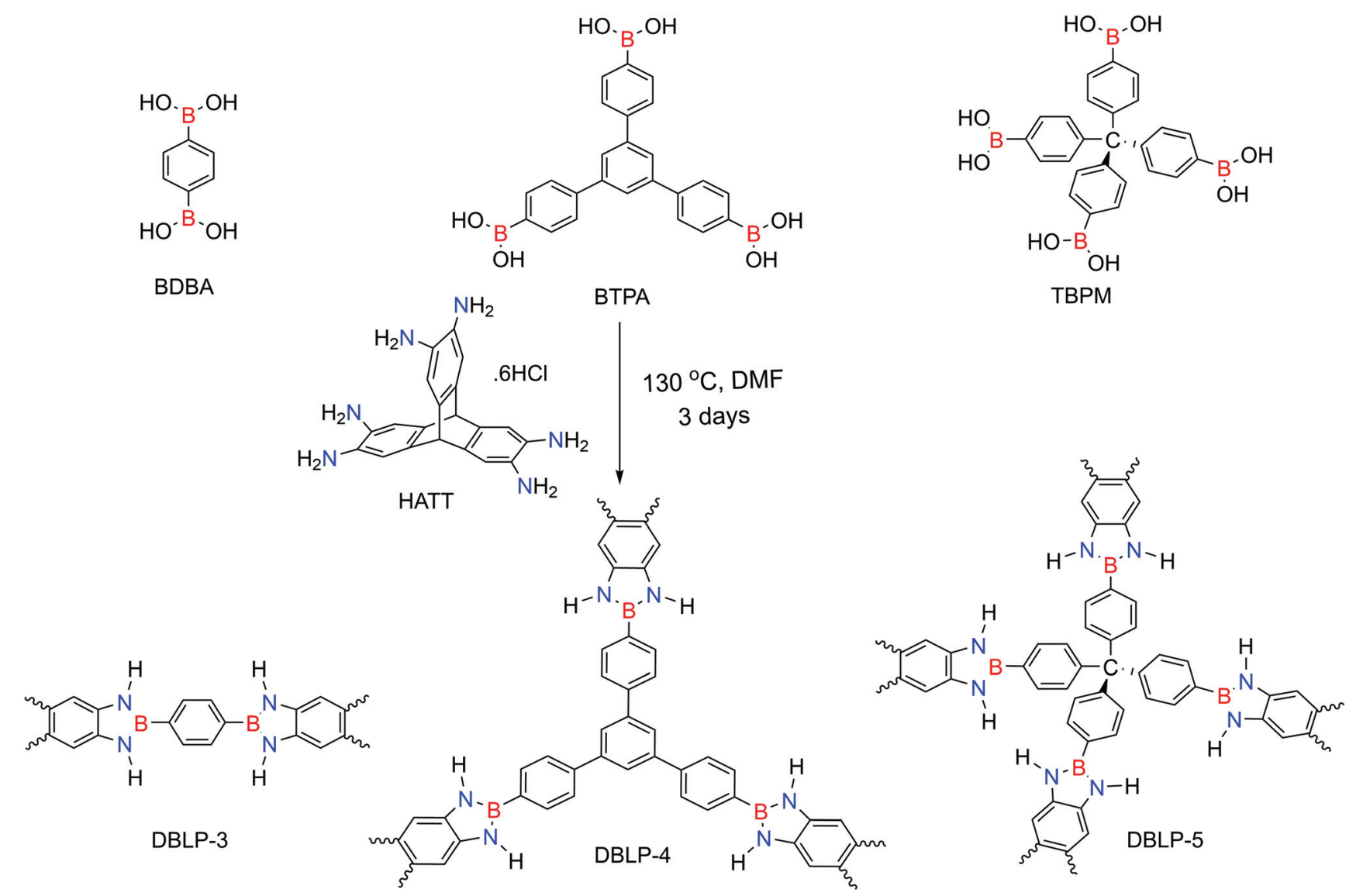

Scheme 1 Synthesis of triptycene-derived diazaborole-linked polymers (DBLPs).

polymers were purified by soaking in THF and acetone to solubilize and remove the unreacted boronic acid and amine containing starting materials. Subsequently, polymers were prepared for the spectral, analytical and porosity measurements by drying under reduced pressure and heating at $120{ }^{\circ} \mathrm{C}$. The chemical composition, stability, and phase purity and the amorphous nature of the DBLPs were established using elemental analysis, FT-IR, solid-state ${ }^{11} \mathrm{~B}$ and ${ }^{13} \mathrm{C}$ CP-MAS, SEM and XRD, as well as porosity measurements. Scanning electron microscopy (SEM) of the polymers revealed aggregated fine particles of variable size in the range of $\sim 0.4$ to $1.0 \mu \mathrm{m}$ (Fig. S1 ESI $\dagger$ ). Thermogravimetric analysis (TGA) showed initial weight loss up to around $100{ }^{\circ} \mathrm{C}$ which corresponds to the removal of adsorbed moisture or residual solvents in the pores then decomposition starts around $350{ }^{\circ} \mathrm{C}$ (Fig. S2 ESI $\dagger$ ). The FT-IR spectrum of DBLPs (Fig. S3 ESI $\dagger$ ) revealed $\mathrm{N}-\mathrm{H}$ stretching at around $3400 \mathrm{~cm}^{-1}$ (free $\mathrm{N}-\mathrm{H}$ ) and disappearance of broad $\mathrm{O}-\mathrm{H}$ vibrations of boronic acid units, while intense new bands appeared at $1423 \mathrm{~cm}^{-1}$ (B-N, double bond character), $1171 \mathrm{~cm}^{-1}$ (B-N, single bond character), and $1012 \mathrm{~cm}^{-1}$ (B-C stretch) that can be assigned to skeleton vibration of the diazaborole ring. ${ }^{32,35-37}$ The solid-state ${ }^{11} \mathrm{~B}$ (Fig. S4 ESI $\dagger$ ) revealed a broad signal ranging from $19.8 \mathrm{ppm}$ to $8.0 \mathrm{ppm}$ which falls in the reported tri-coordinate boron atoms ${ }^{38}$ and the ${ }^{13} \mathrm{C}$ CP-MAS studies (Fig. S4 ESI $\dagger$ ) further support the incorporation of the triptycene and aryl moieties from the boronic acids into the framework of DBLPs.

\subsection{Optical properties}

The impact of copolymerization can also be easily noted from the photophysical properties of DBLPs; we selected one of the polymers, DBLP-4, for UV-Vis studies and compared the results to those of the building units as well as the covalent organic framework that could form upon self-condensation of 1,3,5-tris [4-phenylboronicacid] benzene. Upon exciting DBLP-4 with $340 \mathrm{~nm}$ in DMF, green emission with broad peak ranging from 350 to $680 \mathrm{~nm}$ is observed (Fig. 2). Compared to both triptycene and the triphenyl boronic acid, the excitation peak of DBLP-4 exhibits a bathochromic shift (Fig. 2). Similarly, the emission peak in DBLP-4 shows a red shift. The red shift in both excitation and emission indicates an increased conjugation due to the formation of diazaborole link involving one of the benzene rings from triptycene and the boron part of the triphenyl boronic acid. It is worth noting that DBLP-4 is stable to light and did not exhibit any degradation as the sample was exposed to UV light for 40 minutes according to photobleaching studies (Fig. S5 ESI $\dagger$ ). For comparison, the UV-Vis results for DBLP-3 and DBLP-5 are depicted in Fig. S5 ESI. $\dagger$ Similar photophysical properties results have been reported for nonporous sidechain diazaborole 

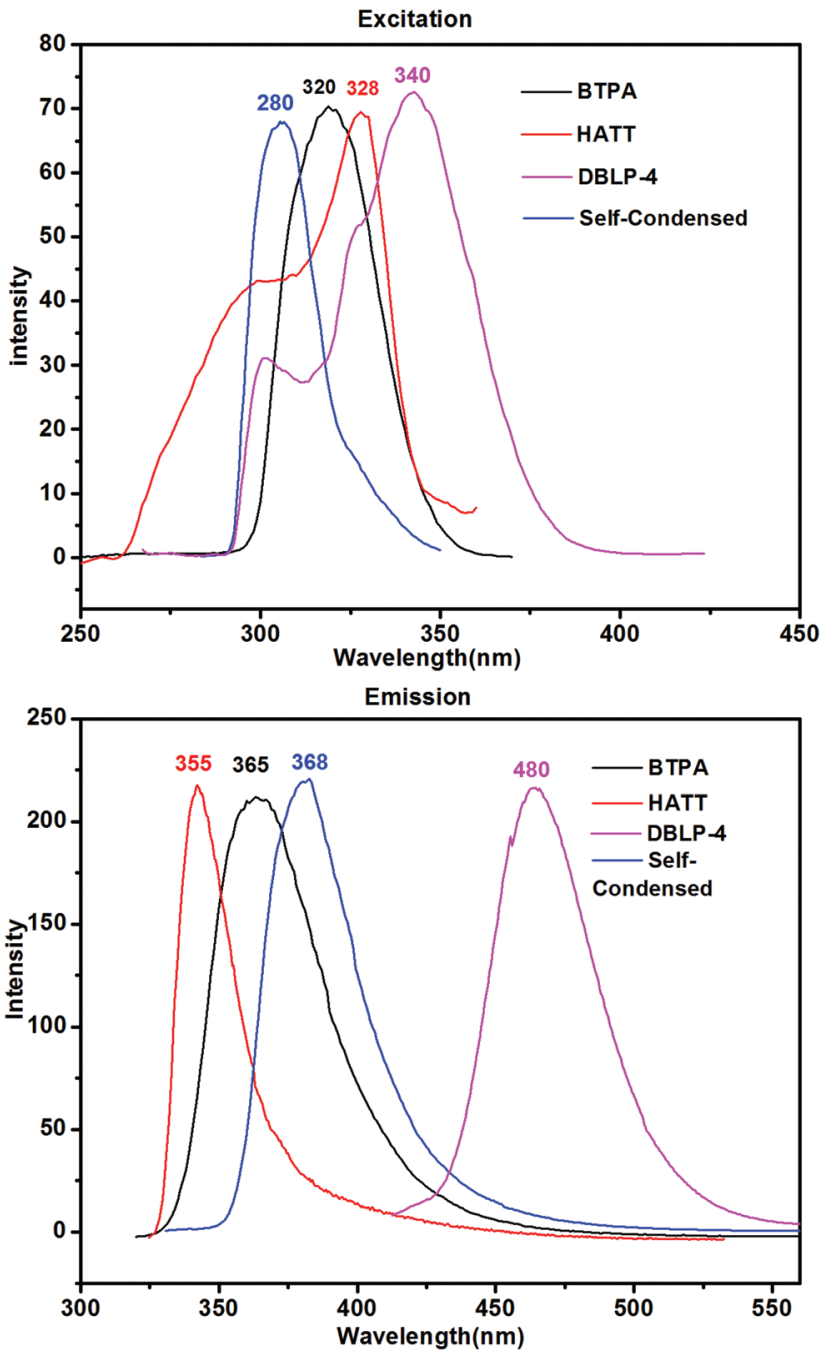

Fig. 2 Excitation and Emission spectra of BTPA, HATT, DBLP-4 and self-condensed BTPA in DMF.

functionalized linear polymers or oligomers linked by diazaborole units. ${ }^{29-32}$ Compared to DBLP-3 and DBLP-5, the emission spectrum of DBLP-4 is red shifted (Fig. S6 ESI $\dagger$ ). This is due to the differences in the structural arrangement of these three different polymers. DBLP-3 has one benzene ring as the central core, DBLP-5 has four benzene rings connected by carbon atom at the central core whereas DBLP-4 has one triphenyl benzene which is highly conjugated. The higher the conjugation the longer the emission wavelength. As these polymers are emissive and have boron atom which is electron deficient, they would be useful for sensing anions such as halides.

\subsection{Porosity and gas uptake studies}

To investigate the porous nature of DBLPs, we performed $\mathrm{Ar}$ porosity measurements at $87 \mathrm{~K}$ (Fig. S8 ESI $\dagger$ ). Samples of purified polymers were degassed at $120{ }^{\circ} \mathrm{C}$ for $12 \mathrm{~h}$ under $1 \times 10^{-5}$ Torr vacuum to remove any adsorbed gases or moisture before sorption measurements. The fully reversible type I-IV iso- therms show a rapid uptake at low pressure $\left(P / P_{0}=0\right.$ to 0.05 bar) and are indicative of microporosity. A minor hysteresis for all samples is consistent with their powdery and flexible nature of organic polymers. Applying the Brunauer-EmmettTeller (BET) model to the sorption branch within the pressure range of $P / P_{0}=0.05-0.15$ resulted in surface areas of 730 $\mathrm{m}^{2} \mathrm{~g}^{-1}$ (DBLP-3), $904 \mathrm{~m}^{2} \mathrm{~g}^{-1}$ (DBLP-4), and $986 \mathrm{~m}^{2} \mathrm{~g}^{-1}$ (DBLP-5). We have recently reported the use of the triptycene building unit in the synthesis of several classes of porous organic polymers; COFs, ${ }^{39}$ azo-linked polymers (ALPs) ${ }^{18}$ and benzimidazole-linked polymers (BILPs). ${ }^{20,21}$ Triptycene is well known for enhancing the porosity of polymers of intrinsic microporosity (PIMs), ${ }^{14}$ shape-persistent case molecules, ${ }^{40}$ metal salphens, ${ }^{41}$ and MOFs. ${ }^{42}$ It possesses high degree of internal molecular free volume (IMFV). ${ }^{43,44}$ Pore size distribution (PSD) studies using nonlocal density functional theory (NLDFT) (Fig. S9 and $10 \mathrm{ESI} \dagger$ ) were used to evaluate the potential impact of network interpenetration and cross-linking on the porosity level of DBLPs. Argon isotherms were fitted with NLDFT and PSD were found to be centered around 6.6, 6.7, and 7.4 $\AA$, while the pore volume was calculated from single point measurements $\left(P / P_{0}=\right.$ 0.95 ) and found to be $0.5,0.52$, and $0.68 \mathrm{cc} \mathrm{g}^{-1}$ for DBLP-3, DBLP-4, and DBLP-5, respectively. The results from PSD studies revealed that the structures of the DBLPs are most likely disordered and highly interpenetrated compared to crystalline COF structures derived from the analogous boronateester linkage. For instance, TDCOF- $5^{39}$ which is analogous to DBLP-3 has much larger pores $(26 \AA)$ and surface area $\left(\mathrm{SA}_{\mathrm{BET}}=\right.$ 2497). These results indicate that the polymerization processes which lead to B-N bond formation in DBLPs seem to have little control over pore metrics. This was not surprising giving the less labile nature of $\mathrm{B}-\mathrm{N}$ when compared to $\mathrm{B}-\mathrm{O}$ bonds. ${ }^{45-47}$

All DBLPs have sub-nanometer pores rich in heteroatoms (C, N, H, and B) which are attractive features for the study of small gas storage and separation applications. Accordingly, gas uptake measurements were collected for $\mathrm{H}_{2}, \mathrm{CO}_{2}$, and $\mathrm{CH}_{4}$ at low pressure (1.0 bar) as shown in Fig. 3. The $\mathrm{CO}_{2}$ gas adsorption performance of DBLPs is depicted in Fig. 3A. The $\mathrm{CO}_{2}$ isotherms collected at $273 \mathrm{~K}$ up to 1 bar are fully reversible and exhibit a steep rise at low pressures. The $\mathrm{CO}_{2}$ sorption of the DBLP-4 found to be $198 \mathrm{mg} \mathrm{g}^{-1}\left(4.50 \mathrm{mmol} \mathrm{g}^{-1}\right)$ at $273 \mathrm{~K}$ and 1 bar which is higher than BLPs (74-128 $\left.\mathrm{mg} \mathrm{g}^{-1}\right),{ }^{24-26}$ BILP-10 $\left(177 \mathrm{mg} \mathrm{g}^{-1}\right),{ }^{19}$ and also wide range of porous organic polymers such as and $-\mathrm{OH}$ functionalized porous organic frameworks (POFs: $4.2 \mathrm{mmol} \mathrm{g}^{-1}$ ), ${ }^{48}$ functionalized CMPs (1.6-1.8 $\left.\mathrm{mmol} \mathrm{g}^{-1}\right),{ }^{49}$ and triptycene-based microporous poly(benzimidazole) networks TBIs (2.7-3.9 mmol g $\left.{ }^{-1}\right) .{ }^{50}$ The $\mathrm{CO}_{2}$ uptake of DBLP-4 is also similar with those of the best performing organic polymers such as BILP-7/4 $\left(4.5 / 5.3 \mathrm{mmol} \mathrm{g}^{-1}\right) .^{21}$

In addition to $\mathrm{CO}_{2}$ capture, hydrogen storage studies have been considered due to their potential use in automotive applications and their abundance and clean aspects. The hydrogen uptake by DBLPs (1.73-2.13 wt\%) at $77 \mathrm{~K}$ and $1 \mathrm{bar}$ (Fig. 3B) are higher than most of the microporous organic 

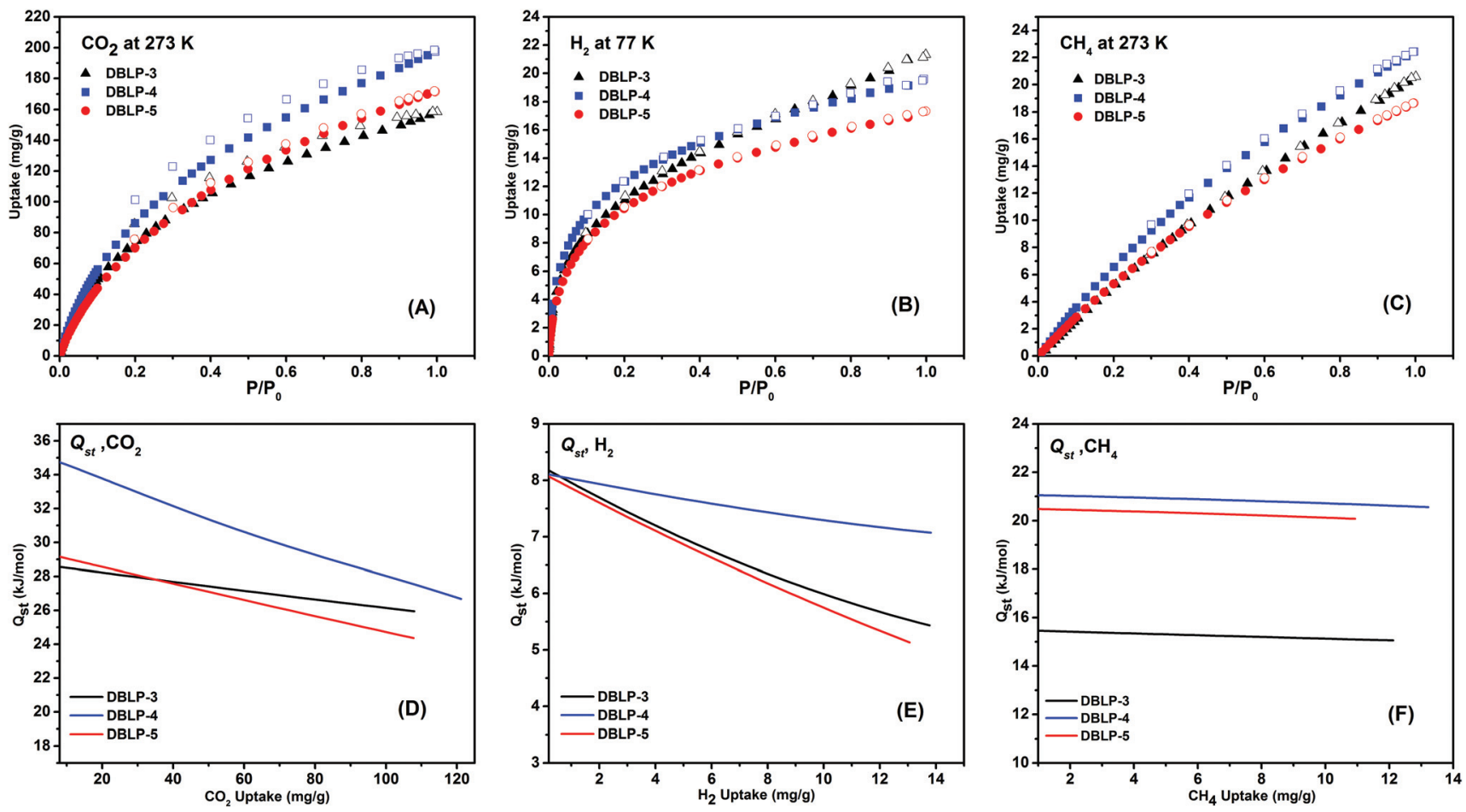

Fig. 3 Gas uptake isotherms: $\mathrm{CO}_{2}(\mathrm{~A}), \mathrm{H}_{2}(\mathrm{~B}), \mathrm{CH}_{4}(\mathrm{C})$, and $\mathrm{Q}_{\mathrm{st}} \mathrm{CO}_{2}(\mathrm{D}), \mathrm{H}_{2}(\mathrm{E})$, and $\mathrm{CH}_{4}(\mathrm{~F})$.

polymers. ${ }^{14,51}$ Additionally, $\mathrm{CH}_{4}$ uptakes were in the range of 18.7-22.4 $\mathrm{mg} \mathrm{g}^{-1}$. The binding affinity of $\mathrm{CO}_{2}, \mathrm{CH}_{4}$ and $\mathrm{H}_{2}$ was calculated from sorption data collected at $273 \mathrm{~K}$ and $298 \mathrm{~K}$ by using the virial method. DBLPs exhibited high heats of adsorption $\left(Q_{\mathrm{st}}\right)$ for $\mathrm{CO}_{2}$ ranging from 28.6 to $35.3 \mathrm{~kJ} \mathrm{~mol}^{-1}$ at low coverage (Fig. 3D and S13 ESI $\dagger$ ). Similar $Q_{\text {st }}$ ranges have been also reported for several porous materials that show high $\mathrm{CO}_{2}$ capturing capacity such as BILPs (26.7-28.8 $\left.\mathrm{kJ} \mathrm{mol}^{-1}\right){ }^{19-21,52}$ PECONFs $\left(26-34 \mathrm{~mol}^{-1}\right)^{53}$ or PI-1 $\left(34 \mathrm{~mol}^{-1}\right){ }^{54}$ The high $Q_{\text {st }}$ values can be attributed to their narrow pores that facilitate $\mathrm{CO}_{2}$-multiwall interactions and the formation of $\mathrm{CO}_{2} \cdots \mathrm{H}-\mathrm{N}$ hydrogen bonding. ${ }^{32}$ Noteworthy, it was reported that the $\mathrm{N}-\mathrm{H}$ sites of diazaborole form hydrogen bonds by intramolecular interactions with oxygen atoms of neighboring quinine units characterized by short $\mathrm{C}=\mathrm{O} \cdots \mathrm{H}-\mathrm{N}$ bonds $(2.09 \AA)$. Therefore, it is most likely that the high bonding affinity and $\mathrm{CO}_{2}$ uptake by DBLPs would benefit from similar interactions. ${ }^{32} \mathrm{~A}$ small depletion in $Q_{\text {st }}$ at higher $\mathrm{CO}_{2}$ loading suggests saturation of favorable $\mathrm{CO}_{2}$ binding sites of DBLPs that become less accessible with increasing $\mathrm{CO}_{2}$ pressure. ${ }^{23,55}$ In a similar way, hydrogen $Q_{\text {st }}$ values were calculated at zero-coverage, the $Q_{\text {st }}$ values for DBLPs are around $8.1 \mathrm{~kJ} \mathrm{~mol}^{-1}$ (Fig. 3E and S14 ESI†). The $Q_{\text {st }}$ values are higher than the values reported for organic polymers such as polyimide networks (5.3-7.0 $\left.\mathrm{kJ} \mathrm{mol}^{-1}\right){ }^{56-58}$ porous aromatic frameworks (PAF-1, $4.6 \mathrm{~kJ} \mathrm{~mol}^{-1}$ ), ${ }^{59}$ porous polymer networks (PPNs, 5.5-7.6 kJ mol${ }^{-1}$ ), ${ }^{60}$ and comparable with BILPs $\left(7.8-8.3 \mathrm{~kJ} \mathrm{~mol}^{-1}\right),{ }^{19-21,52}$ and $-\mathrm{OH}$ functionalized POFs $\left(8.3 \mathrm{~kJ} \mathrm{~mol}^{-1}\right) .{ }^{61}$ Unlike the $\mathrm{CO}_{2}$ uptake, decoration of framework with polar groups does not enhance the methane uptake $^{62}$ as a result of non-polar nature of the methane which is evidenced by relatively low enthalpies of adsorption (15.5 to $21.1 \mathrm{~kJ} \mathrm{~mol}^{-1}$ ) (Fig. S15 ESI $\dagger$ ). Although, framework interaction with methane is weaker than $\mathrm{CO}_{2}$, yet still strong enough to accommodate high methane uptake at low pressures and inline with most porous materials in the field. ${ }^{58,62-64}$

There have been great efforts to design an adsorbent which is selectively capture the targeted gas molecule. $\mathrm{CO}_{2}$ is not the main component in gas mixtures, and selective $\mathrm{CO}_{2}$ removal from mixtures such as flue gas ( $75 \%$ nitrogen) is needed in addition to high capacity for $\mathrm{CO}_{2}$. Therefore, $\mathrm{CO}_{2} / \mathrm{N}_{2}$ and $\mathrm{CO}_{2} /$ $\mathrm{CH}_{4}$ selectivity has been calculated for flue gas and landfill gas, respectively, using Henrỳs law initial slope selectivity calculations which generally give decent assessment for selectivity were applied to single-component gas adsorption isotherms obtained at $273 \mathrm{~K}$ and $298 \mathrm{~K}$ (Fig. 4 and S16, $17 \mathrm{ESI} \dagger$ ) as summarized in Table 1 . Recent selectivity studies of several porous adsorbents demonstrated that high $\mathrm{CO}_{2}$ uptake coupled with narrow pore size are advantageous for selective $\mathrm{CO}_{2}$ capture. ${ }^{65-67}$ Following this trend, DBLP-4 showed higher $\mathrm{CO}_{2} /$ $\mathrm{N}_{2}$ selectivity (51) at $298 \mathrm{~K}$ compared to DBILP-3 (42) and DBLP-5 (35) as shown in Table 1 due to the high $Q_{\text {st }}$ value of DBLP-4. In general, polymers with high $Q_{\text {st }}$ for $\mathrm{CO}_{2}$ result in higher $\mathrm{CO}_{2}$ selectivity, ${ }^{55}$ because they exhibit high $\mathrm{CO}_{2}$ uptake at low pressures. Overall, all DBLPs showed high selectivity for $\mathrm{CO}_{2} / \mathrm{N}_{2}(35-51)$ at $298 \mathrm{~K}$ which is comparable with those of BILPs, ${ }^{19-21,52}$ MOPs, ${ }^{55}$ COPs, ${ }^{68}$ NPOFs, ${ }^{69}$ and ALPs. ${ }^{18}$ Moreover, the $\mathrm{CO}_{2} / \mathrm{CH}_{4}$ selectivity values for all polymers fall in the range of 4.9 to 6.2 . 

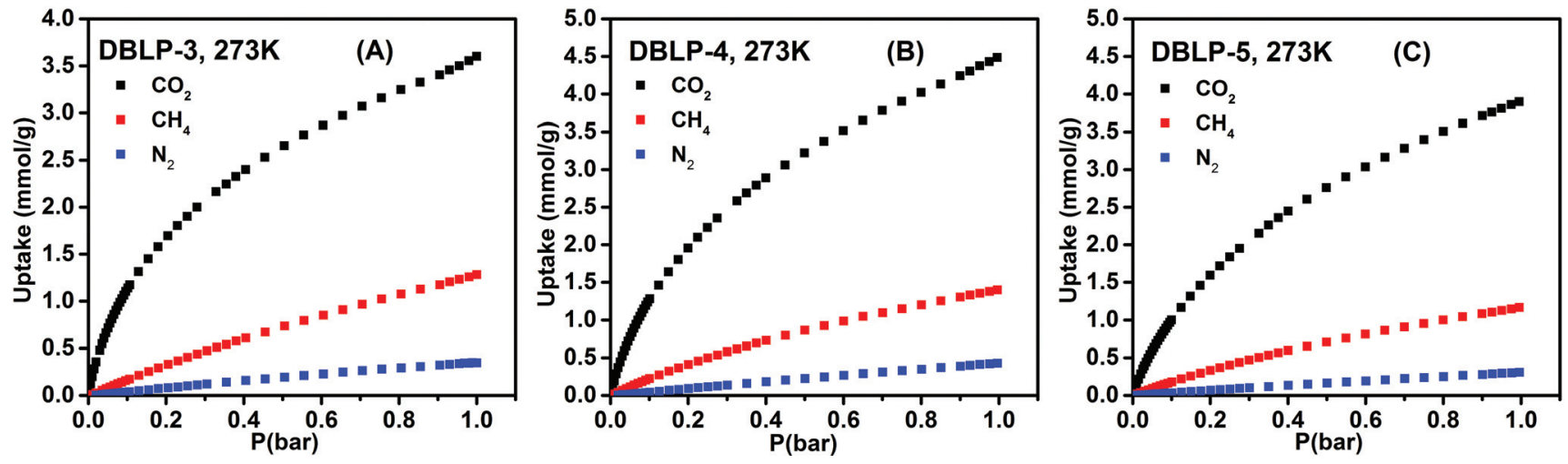

Fig. $4 \mathrm{CO}_{2}, \mathrm{CH}_{4}$, and $\mathrm{N}_{2}$ gas uptake isotherms at $273 \mathrm{~K}$ of DBLPs.

Table 1 Gas uptake and selectivity $\left(\mathrm{CO}_{2} / \mathrm{N}_{2}\right.$ and $\left.\mathrm{CO}_{2} / \mathrm{CH}_{4}\right)$ for DBLPs

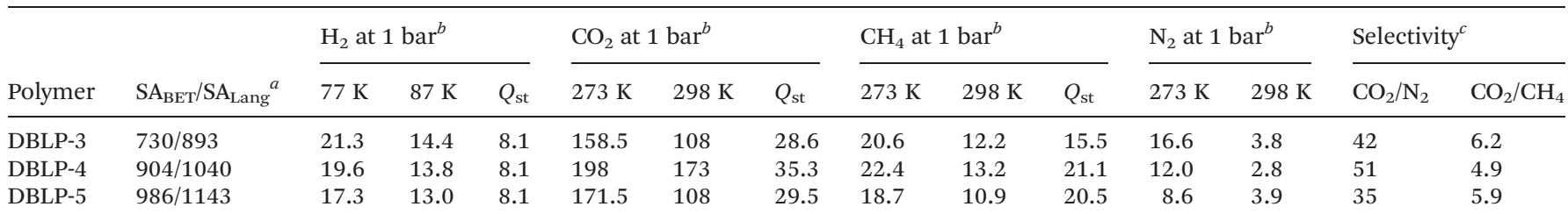

${ }^{a}$ Surface area $\left(\mathrm{m}^{2} \mathrm{~g}^{-1}\right)$ was calculated from Ar isotherm. ${ }^{b}$ Gas uptake in $\mathrm{mg} \mathrm{g}^{-1}$ and the isosteric enthalpies of adsorption $\left(Q_{\mathrm{st}}\right)$ in $\mathrm{kJ}$ mol ${ }^{-1}$. ${ }^{c}$ Selectivity $\left(\mathrm{mol} \mathrm{mol}^{-1}\right)$ was calculated from initial slope calculations at $298 \mathrm{~K}$.

\section{Conclusions}

To conclude, we have successfully synthesized and characterized a new class of porous polymer, named DBLPs and investigated their potential in small gas uptake and separation. DBLPs can be synthesized through condensation reactions between boronic acid building blocks and orthodiaminecontaining monomers with high surface area and subnanometer pore size. These polymers exhibit remarkable $\mathrm{CO}_{2}$ uptake (up to $4.5 \mathrm{mmol} \mathrm{g}^{-1}$ ) and good $\mathrm{CO}_{2}$ selectivity over $\mathrm{N}_{2}$ that can reach up to 51 at 1 bar and $298 \mathrm{~K}$. In addition to high $\mathrm{CO}_{2}$ uptake and selectivity, DBLPs show interesting optical properties which could open the door for other applications.

\section{Acknowledgements}

Research supported by the U.S. Department of Energy, Office of Basic Energy Sciences, Division of Materials Sciences and Engineering under award number DE-SC0002576.

\section{References}

1 D. Wu, F. Xu, B. Sun, R. Fu, H. He and K. Matyjaszewski, Chem. Rev., 2012, 112, 3959-4015.

2 Y. Zhang and S. N. Riduan, Chem. Soc. Rev., 2012, 41, 20832094.

3 P. Kaur, J. T. Hupp and S. T. Nguyen, ACS Catal., 2011, 1, 819-835.
4 S. Das, P. Heasman, T. Ben and S. Qiu, Chem. Rev., 2017, 117, 1515-1563.

5 A. G. Slater and A. I. Cooper, Science, 2015, 348, 988-998.

6 R. Dawson, A. I. Cooper and D. J. Adams, Prog. Polym. Sci., 2012, 37, 530-563.

7 H. M. El-Kaderi, J. R. Hunt, J. L. Mendoza-Cortés, A. P. Côté, R. E. Taylor, M. O'Keeffe and O. M. Yaghi, Science, 2007, 316, 268-272.

8 C. S. Diercks and O. M. Yaghi, Science, 2017, 355, 923-931.

9 P. J. Waller, F. Gándara and O. M. Yaghi, Acc. Chem. Res., 2015, 48, 3053-3063.

10 S.-Y. Ding and W. Wang, Chem. Soc. Rev., 2013, 42, 548-568.

11 X. Feng, X. Ding and D. Jiang, Chem. Soc. Rev., 2012, 41, 6010-6022.

12 T. Ben and S. Qiu, CrystEngComm, 2013, 15, 17-26.

13 M. R. Liebl and J. Senker, Chem. Mater., 2013, 25, 970-980.

14 B. S. Ghanem, M. Hashem, K. D. M. Harris, K. J. Msayib, M. Xu, P. M. Budd, N. Chaukura, D. Book, S. Tedds, A. Walton and N. B. McKeown, Macromolecules, 2010, 43, 5287-5294.

15 Q. Chen, M. Luo, P. Hammershøj, D. Zhou, Y. Han, B. W. Laursen, C.-G. Yan and B.-H. Han, J. Am. Chem. Soc., 2012, 134, 6084-6087.

16 M. G. Rabbani, A. K. Sekizkardes, Z. Kahveci, T. E. Reich, R. Ding and H. M. El-Kaderi, Chem. - Eur. J., 2013, 19, 3324-3328.

17 P. Pandey, A. P. Katsoulidis, I. Eryazici, Y. Wu, M. G. Kanatzidis and S. B. T. Nguyen, Chem. Mater., 2010, 22, 4974-4979. 
18 P. Arab, M. G. Rabbani, A. K. Sekizkardes, T. Islamoglu and H. M. El-Kaderi, Chem. Mater., 2014, 26, 1385-1392.

19 M. G. Rabbani, A. K. Sekizkardes, O. M. El-Kadri, B. R. Kaafarani and H. M. El-Kaderi, J. Mater. Chem., 2012, 22, 25409-25417.

20 M. G. Rabbani, T. E. Reich, R. M. Kassab, K. T. Jackson and H. M. El-Kaderi, Chem. Commun., 2012, 48, 1141-1143.

21 M. G. Rabbani and H. M. El-Kaderi, Chem. Mater., 2012, 24, 1511-1517.

22 M. G. Rabbani and H. M. El-Kaderi, Chem. Mater., 2011, 23, 1650-1653.

23 S. Altarawneh, S. Behera, P. Jena and H. M. El-Kaderi, Chem. Commun., 2014, 3571-3574.

24 K. T. Jackson, M. G. Rabbani, T. E. Reich and H. M. ElKaderi, Polym. Chem., 2011, 2, 2775-2777.

25 K. T. Jackson, T. E. Reich and H. M. El-Kaderi, Chem. Commun., 2012, 48, 8823-8825.

26 T. E. Reich, S. Behera, K. T. Jackson, P. Jena and H. M. ElKaderi, J. Mater. Chem., 2012, 22, 13524-13528.

27 T. E. Reich, K. T. Jackson, S. Li, P. Jena and H. M. ElKaderi, J. Mater. Chem., 2011, 21, 10629-10632.

28 W. Zhao, S. Han, X. Zhuang, F. Zhang, Y. Mai and X. Feng, J. Mater. Chem. A, 2015, 3, 23352-23359.

29 A. Chrostowska, M. Maciejczyk, A. Dargelos, P. Baylere, L. Weber, V. Werner, D. Eickhoff, H. G. Stammler and B. Neumann, Organometallics, 2010, 29, 5192-5198.

30 S. Hayashi and T. Koizumi, Polym. Chem., 2012, 3, 613-616.

31 T. Kojima, D. Kumaki, J.-I. Nishida, S. Tokito and Y. Yamashita, J. Mater. Chem., 2011, 21, 6607-6613.

32 J. Nishida, T. Fujita, Y. Fujisaki, S. Tokito and Y. Yamashita, J. Mater. Chem., 2011, 21, 16442-16447.

33 A. B. Morgan, J. L. Jurs and J. M. Tour, J. Appl. Polym. Sci., 2000, 76, 1257-1268.

34 I. G. C. Coutts, H. R. Goldschm and O. C. Musgrave, J. Chem. Soc. C, 1970, 488-493.

35 R. J. Doerksen and A. J. Thakkar, J. Phys. Chem. A, 1999, 103, 2141-2151.

36 I. Yamaguchi, T. Tominaga and M. Sato, Polym. Int., 2009, $58,17-21$.

37 P. I. Paetzold, Z. Anorg. Allg. Chem., 1963, 326, 64-69.

38 T. Jaschke and M. Jansen, J. Mater. Chem., 2006, 16, 27922799.

39 Z. Kahveci, T. Islamoglu, G. A. Shar, R. Ding and H. M. ElKaderi, CrystEngComm, 2013, 15, 1524-1527.

40 M. Mastalerz, M. W. Schneider, I. M. Oppel and O. Presly, Angew. Chem., Int. Ed., 2011, 50, 1046-1051.

41 J. H. Chong, S. J. Ardakani, K. J. Smith and M. J. MacLachlan, Chem. - Eur. J., 2009, 15, 11824-11828.

42 S. I. Vagin, A. K. Ott, S. D. Hoffmann, D. Lanzinger and B. Rieger, Chem. - Eur. J., 2009, 15, 5845-5853.

43 C.-F. Chen, Chem. Commun., 2011, 47, 1674-1688.

44 N. T. Tsui, A. J. Paraskos, L. Torun, T. M. Swager and E. L. Thomas, Macromolecules, 2006, 39, 3350-3358.

45 L. Weber, V. Werner, M. A. Fox, T. B. Marder, S. Schwedler, A. Brockhinke, H. G. Stammler and B. Neumann, Dalton Trans., 2009, 1339-1351, DOI: 10.1039/B815931a.
46 F. Jakle, Coord. Chem. Rev., 2006, 250, 1107-1121.

47 N. Matsumi, K. Kotera, K. Naka and Y. Chujo, Macromolecules, 1998, 31, 3155-3157.

48 J. An, S. J. Geib and N. L. Rosi, J. Am. Chem. Soc., 2009, 132, 38-39.

49 B. Li, Y. Duan, D. Luebke and B. Morreale, Appl. Energy, 2013, 102, 1439-1447.

50 H. A. Gasteiger and N. M. Marković, Science, 2009, 324, 48-49.

51 A. Thomas, P. Kuhn, J. Weber, M.-M. Titirici and M. Antonietti, Macromol. Rapid Commun., 2009, 30, 221236.

52 M. G. Rabbani and H. M. El-Kaderi, Chem. Mater., 2011, 23, 1650-1653.

53 P. Mohanty, L. D. Kull and K. Landskron, Nat. Commun., 2011, 2, 1-6.

54 A. Laybourn, R. Dawson, R. Clowes, J. A. Iggo, A. I. Cooper, Y. Z. Khimyak and D. J. Adams, Polym. Chem., 2012, 3, 533537.

55 R. Dawson, A. I. Cooper and D. J. Adams, Polym. Int., 2013, 62, 345-352.

56 Z. Wang, B. Zhang, H. Yu, L. Sun, C. Jiao and W. Liu, Chem. Commun., 2010, 46, 7730-7732.

57 O. K. Farha, A. M. Spokoyny, B. G. Hauser, Y.-S. Bae, S. E. Brown, R. Q. Snurr, C. A. Mirkin and J. T. Hupp, Chem. Mater., 2009, 21, 3033-3035.

58 O. K. Farha, Y.-S. Bae, B. G. Hauser, A. M. Spokoyny, R. Q. Snurr, C. A. Mirkin and J. T. Hupp, Chem. Commun., 2010, 46, 1056-1058.

59 T. Ben, H. Ren, S. Ma, D. Cao, J. Lan, X. Jing, W. Wang, J. Xu, F. Deng, J. M. Simmons, S. Qiu and G. Zhu, Angew. Chem., Int. Ed., 2009, 48, 9457-9460.

60 W. Lu, D. Yuan, D. Zhao, C. I. Schilling, O. Plietzsch, T. Muller, S. Bräse, J. Guenther, J. Blümel, R. Krishna, Z. Li and H.-C. Zhou, Chem. Mater., 2010, 22, 59645972.

61 A. P. Katsoulidis and M. G. Kanatzidis, Chem. Mater., 2011, 23, 1818-1824.

62 T. Islamoglu, T. Kim, Z. Kahveci, O. M. El-Kadri and H. M. El-Kaderi, J. Phys. Chem. C, 2016, 120, 2592-2599.

63 D. Britt, D. Tranchemontagne and O. M. Yaghi, Proc. Natl. Acad. Sci. U. S. A., 2008, 105, 11623-11627.

64 H. Furukawa and O. M. Yaghi, J. Am. Chem. Soc., 2009, 131, 8875-8883.

65 C. E. Wilmer, O. K. Farha, Y.-S. Bae, J. T. Hupp and R. Q. Snurr, Energy Environ. Sci., 2012, 5, 9849-9856.

66 P. Nugent, Y. Belmabkhout, S. D. Burd, A. J. Cairns, R. Luebke, K. Forrest, T. Pham, S. Ma, B. Space, L. Wojtas, M. Eddaoudi and M. J. Zaworotko, Nature, 2013, 495, 8084.

67 P.-Z. Li and Y. Zhao, Chem. - Asian J., 2013, 8, 16801691.

68 Z. Xiang, X. Zhou, C. Zhou, S. Zhong, X. He, C. Qin and D. Cao, J. Mater. Chem., 2012, 22, 22663-22669.

69 T. Islamoglu, M. Gulam Rabbani and H. M. El-Kaderi, J. Mater. Chem. A, 2013, 1, 10259-10266. 